\title{
Colocalization of Taurine- and Cysteine Sulfinic Acid Decarboxylase- like Immunoreactivity in the Cerebellum of the Rat with Monoclonal Antibodies Against Taurine
}

\author{
K. R. Magnusson, J. E. Madl, J. R. Clements, J.-Y. Wu, ${ }^{1}$ A. A. Larson, and A. J. Beitz \\ Department of Veterinary Biology, College of Veterinary Medicine, University of Minnesota, St. Paul, Minnesota 55108, \\ and 'Department of Physiology, The Milton S. Hershey Medical Center, Pennsylvania State University, Hershey, \\ Pennsylvania 17033
}

Two monoclonal antibodies against fixative-modified taurine, Tau1 and Tau2, were produced, characterized, and used in the present study to analyze the distribution of taurine in the cerebellum of the rat. In addition, immunohistochemical colocalization experiments were performed to determine whether cerebellar neurons contain both taurine and its synthesizing enzyme, cysteine sulfinic acid decarboxylase (CSADC). In ELISAs, both Tau1 and Tau2 displayed high affinities for taurine conjugated to various carrier proteins and possessed some cross-reactivity for other amino acids which are present in lower concentrations in the brain than taurine. Tau2 was found to recognize only taurine and hypotaurine when paraformaldehyde was used to fix the amino acids to carrier proteins. With the use of glutaraldehyde fixation, Tau 1 cross-reacted with conjugates of beta-alanine and hypotaurine and Tau2 cross-reacted strongly with conjugates of cysteic acid and hypotaurine and weakly with cysteine sulfinic acid. Despite different cross-reactivities, Tau1 and Tau2 exhibited almost identical patterns of neuronal staining in bands of Purkinje cells in the cerebellum. Staining of Purkinje cell dendrites was more prominent than staining of the soma. Light immunoreactivity was present in Golgi, stellate, and basket cells. A scattered population of granule cells displayed taurine-like immunoreactivity at the electron microscopic level. Immunostaining was identified in some terminals in the Purkinje cell layer and in a limited number of mossy fibers. Tau2-like immunoreactivity was colocalized with CSADC-Iike Immunoreactlvity In the cerebellar neurons described above. These immunoreactive cells may represent a subpopulation of neurons that contain a higher concentration of taurine than neighboring cells due to their ability to synthesize taurine. The intense immunoreactive staining of Purkinje cell dendrites provides support for the hypothesis that calcium-dependent release of taurine in the cerebellum may originate primarily from dendritic rather than synaptic processes and suggests a neuromodulator role for taurine in the cerebellum.

\footnotetext{
Received Jan. 11, 1988; revised May 2, 1988; accepted May 6, 1988.

We wish to thank L. Wiener, G. Zhang, J. Hautman, and L. Schilb for their excellent technical support. This work was supported by NIH Physician Scientist Award AG00329 to K.R.M., NIH Clinical Investigator Award NS01 105 to J.E.M. NIH First Award DE08185 to J.R.C., NIH Grants DAO4090 to A.A.L. and NS19208 and DE06682 to A.J.B. and NSF Grant BNS-8607520 to A.J.B.

Correspondence should be addressed to Dr. Kathy R. Magnusson, $295 \mathrm{AnSci} /$ VetMed Bldg., 1988 Fitch Avenue, University of Minnesota, St. Paul, MN 55108.

Copyright (c) 1988 Society for Neuroscience $0270-6474 / 88 / 124551-14 \$ 02.00 / 0$
}

Taurine is an abundant amino acid in the mammalian CNS (Huxtable and Sebring, 1986). Although it is present in high concentrations, taurine exhibits a slight differential distribution in the brain. Higher concentrations have been reported in cerebrum, cerebellum, and hippocampus compared with brain stem or spinal cord (Agrawal et al., 1971; Lombardini, 1976; Palkovits et al., 1986). Within the cerebellum, differences in taurine concentrations also exist between different cell layers, with the molecular and Purkinje cell layers containing higher concentrations of taurine than the granule cell layer or white matter (Nadi et al., 1977; McBride and Frederickson, 1980). These differential distributions imply that taurine may have a functional role in the CNS, in general, and within the cerebellum, in particular. There is evidence suggesting that taurine can function as a ncurotransmitter (Oja and Lahdesmaki, 1974; Frederickson et al., 1978; McBride and Frederickson, 1980), a neuromodulator (Izumi et al., 1978; Kontro and Oja, 1978, 1983; Oja and Kontro, 1978; Kuriyama, 1980), and a stabilizer of excitable membranes (Schaffer et al., 1980; Hastings et al., 1985).

Taurine satifies several of the criteria for classification as a neurotransmitter and/or neuromodulator in the mammalian cerebellum. Taurine produces a hyperpolarization of neurons in the cerebellum (McBride and Frederickson, 1980; Yeh et al., 1981; Okamoto et al., 1983a-c), including a majority of, but not all, Purkinje cells (Frederickson et al., 1978). This hyperpolarization is associated with an increased chloride conductance (Okamoto et al., 1983b). Electrically stimulated, calciumdependent release of taurine from cerebellar slices has been demonstrated (Bernardi et al., 1978). Cerebellar neurons have the ability to accumulate tritiated taurine (Assumpcao et al., 1979; Chan-Palay et al., 1982a), and rat brain synaptosomes have been shown to take up taurine in a sodium-dependent, high-affinity manner (Meiner et al., 1980). The synergistic effects of taurine and GABA on cerebellar neurons suggest the presence of a receptor for taurine that is distinct from the $\mathrm{GABA}$ receptor (Frederickson et al., 1978). A taurine antagonist, TAG (6-aminomethyl-3-methyl-4H,1,2,4-benzothiadiazine-1,1-dioxide), has been identified (Yarborough et al., 1981) and shown to selectively antagonize the effect of taurine on Purkinje cell dendrites (Okamoto et al., 1983c). The selective nature of this antagonist, however, has been questioned in studies of the spinal cord (Curtis et al., 1982). Changes in taurine concentration occur in dominantly inherited cerebellar atrophies such as olivopontocerebellar atrophy (Perry, 1978) and may be significant in Friedreich's ataxia (Barbeau et al., 1982). Several studies suggest that taurine 
may be used by stellate interneurons in the cerebellum as a neurotransmitter (Nadi et al., 1977; Frederickson et al., 1978; McBride and Frederickson, 1980; Okamoto and Sakai, 1980; Okamoto et al., 1983c).

Until recently, immunohistochemical localization of taurine within neurons and terminals was hampered by the lack of a specific marker. Wu (1982) prepared and characterized a polyclonal antiserum specific for purified bovine cysteine sulfinic acid decarboxylase (CSADC), an enzyme involved in the metabolism of taurine. CSADC-like immunoreactivity was found to be present in sagittal microbands within the cerebellar cortex. The CSADC antibody labels Purkinje, stellate, basket, and Golgi cells within these microzones (Chan-Palay et al., 1982a, b; Wu et al., 1986). Neurons within the deep cerebellar nuclei are also labeled with CSADC antiserum. Several groups (Madsen et al., 1985; Campistron et al., 1986; Tomida and Kimura, 1987) have recently produced and characterized 3 separate polyclonal antisera raised against taurine conjugated to carrier proteins. They report the presence of taurine-like immunoreactivity in essentially all Purkinje cells throughout the cerebellar cortex and rarely in stellate and basket cells. Yoshida and coworkers (1986), however, reported staining of many, but not all, Purkinje cells with a different polyclonal taurine antiserum.

In the present study, we developed and characterized 2 monoclonal antibodies against taurine conjugated to keyhole limpet hemocyanin (KLH) and report the immunohistochemical localization of taurine in the cerebellum of the rat. Taurine immunostaining was examined using light and electron microscopy and the distribution of taurine-like immunoreactivity was compared with that obtained by others using polyclonal taurine antisera. The taurine-like immunoreactive labcling pattern we obtained in the cerebellum, with the use of paraformaldehyde fixation, resembled that reported by Chan-Palay et al. (1982b) for CSADC-like immunoreactivity and Yoshida et al. (1986) for taurine-like immunoreactivity. In addition, double-labeling studies demonstrated that taurine-like immunoreactivity was colocalized with CSADC-like immunoreactivity in cerebellar neurons.

\section{Materials and Methods}

\section{Antibody production and characterization}

Production of monoclonal antibodies. The original immunogen for this study was produced by conjugating taurine to keyhole limpet hemocyanin (KLH) with the use of glutaraldehyde-borohydride (Madl et al., 1986). Malc Balb/c/umc micc were immunized over a 4 week period and spleen cells from these mice were fused with P3x63-Ag8.653 myeloma cells as previously described (Madl et al., 1987). Culture supernatants from wells containing fused cells were screened for reactivity with the original immunogen using enzyme-linked immunosorbent assay (ELISA) (Madl et al., 1986). Cell lines producing supernatants, which had ELISA reactivity for taurine/KLH but not KLH treated with glutaraldehyde-borohydride, were examined for immunocytochemical staining of brain sections. Two cell lines, Taul and Tau2, were found to produce antibodies capable of tissue staining and also possessed ELISA reactivity for the original immunogen but not the carrier protein. These 2 cell lines were subcloned by limiting dilution and the antibodies produced were isotyped using the mouse monoclonal antibody subisotyping kit from Hyclone Laboratories (Logan, UT). Ascites fluid from these 2 cell lines was produced in pristane-primed mice as previously described (Madl et al., 1986).

Antibody reactivity for fixed small molecules. Fixation of small molecules and subsequent immunoreactivity was tested and quantified using ELISA systems that model the fixation and immunoreactivity of these molecules in tissue. Immulon I ELISA plates (Fisher Scientific, Minneapolis, MN) were coated with $10 \mu \mathrm{g} / \mathrm{ml}$ of thyroglobulin in $0.05 \mathrm{M}$ bicarbonate buffer (pH 9.6, $100 \mu \mathrm{l} /$ well) overnight at room temperature.
Wells were washed 3 times with PBS $(0.1 \mathrm{M}, \mathrm{pH} 7.2)$ containing $0.05 \%$ Tween 20 (Sigma, St. Louis) between each incubation step of this procedure, unless otherwise noted. Amino acids, at various concentrations in PBS, were incubated in the wells with either $5 \%$ glutaraldehyde or with a mixture of $0.2 \mathrm{M}$ Sorensons buffer (pH 7.2) and PBS with $4 \%$ paraformaldehyde. Plates were blocked with $1 \%$ BSA for $1 \mathrm{hr}$. One hundred microliters of culture supernatant or ascitic fluid in PBS were incubated for $1.5 \mathrm{hr}$ in the wells. The indirect immunoperoxidase or avidin-biotin staining methods were used to quantify immunoreactivity.

For the indirect-immunoperoxidase ELISA, $100 \mu 1$ of peroxidaselabeled, goat anti-mouse antiserum (Boehringer Mannheim, Indianapolis, IN), diluted 1:1000 in PBS, was incubated in the wells for $1 \mathrm{hr}$. Antibody labeling in the wells was visualized by reaction with $o$-phenylenediamine $(5 \mathrm{mg} / 12.5 \mathrm{ml}$, Sigma) in citrate buffer $(0.03 \mathrm{M}, \mathrm{pH})$ containing hydrogen peroxide $\left(50 \mu \mathrm{l}\right.$ of $\left.3 \% \mathrm{H}_{2} \mathrm{O}_{2} / 12.5 \mathrm{ml}\right)$. The absorbance of each well was read at $490 \mathrm{~nm}$.

For the avidin-biotin ELISA, $100 \mu \mathrm{l}$ of biotinylated anti-mouse antibody (Vectastain ABC, Vector Labs, Burlingame, CA), diluted 1:1 from the kit concentration in PBS, was added to the wells and incubated for $0.5 \mathrm{hr}$. Avidin-biotin complex $(100 \mu \mathrm{l}$; ABC) was diluted $1: 1$ in PBS, added to the wells, and incubated for $0.5 \mathrm{hr}$. The wells were washed 6 times with PBS and substrate-chromagen was added as above. Absorbance was quantified at $490 \mathrm{~nm}$.

Antibody affinity for fixed amino acids evaluated by inhibition ELISA. Conjugates of amino acids fixed to carrier protein were made by reacting $20 \mathrm{mg}$ of carrier protein with $0.218 \mathrm{mmol}$ of amino acid in $6 \mathrm{ml}$ of PBS at $\mathrm{pH} 7.2$ for $1 \mathrm{hr}$ in 5\% glutaraldehyde followed by dialysis in PBS. Antibodies were preincubated for at least $1.5 \mathrm{hr}$ with these amino acid conjugates before use in inhibition ELISA assays. Either the indirect immunoperoxidase or the ABC ELISA was then carried out as described above on plates coated overnight with $2 \mu \mathrm{g} / \mathrm{ml}$ of Tau/KLH at room temperature. The ratios of the concentrations of amino acid conjugates producing $50 \%$ of the uninhibited ELISA reactivity were used to calculate the percent cross-reactivity of the antibodies for the amino acids.

\section{Immunohistochemistry}

Forty-four male Sprague-Dawley rats (250-330 gm) were used for studies on the light and electron microscopic immunohistochemical localization of Taul and Tau2 antibodies and colocalization of Tau2 and CSADC antisera. Characterization of the CSADC antiserum has been previously described (Wu, 1982). Rats were anesthetized with chloral hydrate and sacrificed by transcardial perfusion with $100 \mathrm{ml}$ calciumfree Tyrode's solution followed by $450 \mathrm{ml}$ of one of 3 fixatives: $4 \%$ paraformaldehyde (Tau2 and Tau $2 / \mathrm{CSA} . \mathrm{DC}$ ), $4 \%$ paraformaldehyde/ $0.2-0.4 \%$ glutaraldehyde (Tau1, Tau 2 , and CSADC), or $5 \%$ glutaraldehyde (Tau1 and Tau2). Brains were removed and postfixed overnight in the same fixative with which they were perfused.

Brains were sectioned $(30-50 \mu \mathrm{m})$ in the coronal or horizontal plane with the use of a Vibratome. Free-floating sections were processed with the Vectastain avidin-biotin-peroxidase method (Vector Labs, Burlingame, CA) as follows, with 3 rinses in PBS following each incubation step. Adjacent tissue sections were incubated overnight with 1 of 3 primary antibodies, diluted in PBS $+0.3 \%$ Triton, and either normal horse serum (Tau1 and Tau2) or normal goat serum (CSADC). Optimum primary antibody dilutions (dilution ranges in parenthesis) were as follows: Tau2 culture supernatant, 1:640 (1:40-1:640), Taul culture supernatant, 1:100 (1:40-1:640), or CSADC antiserum, 1:400 (1:400$1: 1000$ ). Sections were incubated for $1 \mathrm{hr}$ in secondary biotinylated antibody diluted 1:4 in PBS and $1 \mathrm{hr}$ in avidin-biotin-peroxidase complex $(A B C)$ diluted $1: 4$ in PBS. Sections were reacted with diaminobenzidine (DAB) and hydrogen peroxide to produce a brown homogeneous reaction product.

Adjacent $50 \mu \mathrm{m}$ sections stained with either Tau2, Tau1, or CSADC were compared at the light microscopic level for similarity of staining. The location of stained Purkinje cell perikarya was mapped with the use of a camera lucida attachment on an Olympus microscope.

Tissue from 16 rats was processed for electron microscopic immunohistochemical localization of taurine. Animals for electron microscopy were anesthetized with chloral hydrate and perfused sequentially with $100 \mathrm{ml}$ of calcium-free Tyrode's solution and $450 \mathrm{ml}$ of $4 \%$ paraformaldehyde and $0.3 \%$ glutaraldehyde. Tissue sections were processed as for light microscopy, except that Triton-X100 was not used in any of the incubating solutions. Following visualization of the taurine antibody complex with DAB and hydrogen peroxide, tissue sections were thoroughly rinsed in PBS, immersed for $1 \mathrm{hr}$ in buffered $2 \%$ osmium te- 


\section{A. Tau-1 Reactivity for Glutaraldehyde-fixed Amino Acids}

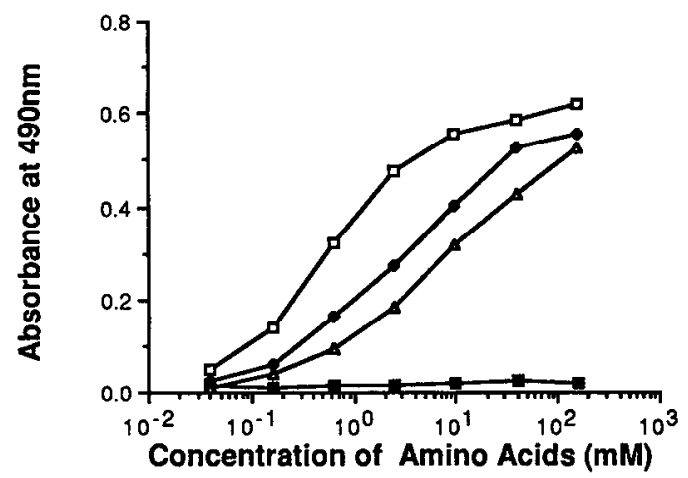

B. Tau-2 Reactivity for Glutaraldehyde-fixed Amino acids

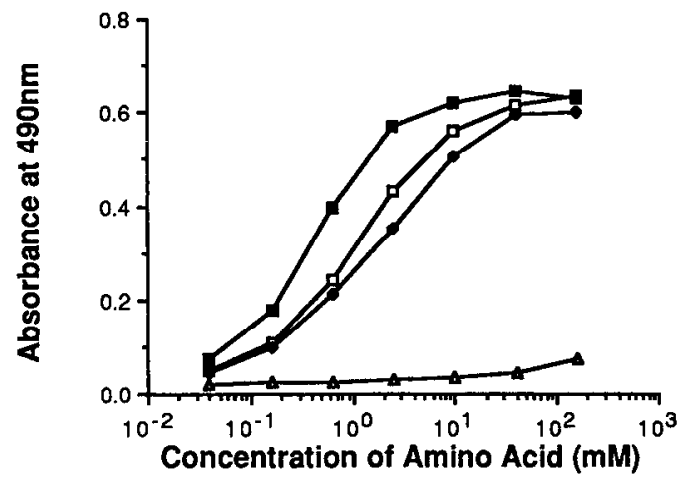

Figure 1. ELISA reactivity of Tau1 and Tau2 for amino acids conjugated by glutaraldehyde to thyroglobulin. Each point represents the mean absorbance of 3 replicate wells using the indirect immunoperoxidase ELISA method. $A$, Taul culture supernatant diluted 1:20 in PBS. $B$, Tau2 culture supernatant diluted 1:20 in PBS.

troxide, rinsed in PBS, and dehydrated in a graded series of ethanol solutions. Tissue sections were infiltrated with either Polybed 812 or Spurr resin (Polysciences, Warrington, PA) and embedded between glass slides coated with dichlorodimethylsilane. Polymerized tissue sections were examined with light microscopy, and areas of interest were scribed, mounted on blocks, and sectioned. All thin sections were examined unstained at $40 \mathrm{kV}$ on a Zeiss $10 \mathrm{EM}$.

\section{Colocalization studies}

Eleven male Sprague-Dawley rats were used for colocalization studies. Rats were perfused, as above, with $4 \%$ paraformaldehyde. Sections used for double-labeling studies were incubated with either the Tau2 (1:640) or CSADC $(1: 400)$ antisera overnight and processed as described above, with the exception that the secondary biotinylated antibody and $A B C$ were diluted 1:8 in PBS. The DAB reaction was followed by an avidinbiotin blocking step to prevent cross-reactivity between markers. Tissue was incubated for $20 \mathrm{~min}$ in excess avidin, rinsed with PBS, incubated in excess biotin for $20 \mathrm{~min}$, and rinsed with PBS. Tissue sections were incubated overnight in normal serum (see above) and the alternate primary antibody. Sections were incubated, as above, in biotinylated secondary antibody and ABC. Benzidine dihydrochloride (BDIC) was used as the chromagen for the second marker to produce a blue granular reaction product. The BDHC procedure was modified from Lakos and Basbaum (1986) and Sugimoto et al. (1985).

Briefly, sections were prewashed in $0.1 \mathrm{M}$ sodium acetate buffer $\mathrm{pH}$ $6.5)$. Four solutions were prepared: $1, \mathrm{BDHC}(20 \mathrm{mg})$ dissolved in 18 $\mathrm{ml}$ ethanol $(100 \%)$ and $40 \mathrm{ml}$ distilled water, with heat to $<40^{\circ} \mathrm{C}$ to dissolve; 2 , sodium nitroprusside $\left(62.5 \mathrm{mg} / 3 \mathrm{ml} \mathrm{H}_{2} \mathrm{O}\right) ; 3$, sodium acetate buffer $(0.2 \mathrm{M}, \mathrm{pH} 6.5)$; and $4,3 \% \mathrm{H}_{2} \mathrm{O}_{2}$.

The suggested ratio of solutions is as follows: $3.75 \mathrm{ml}$ of solution 1 , $50 \mu \mathrm{l}$ of solution $2,600 \mu \mathrm{l}$ of solution 3 , and $15 \mu \mathrm{l}$ of solution 4 . Optimum
Table 1. Reactivities of monoclonal antibodies for glutaraldehydefixed amino acids

\begin{tabular}{lrr} 
& \multicolumn{2}{c}{$\begin{array}{c}\text { ELISA reactivity } \\
\text { (\% taurine reactivity) }\end{array}$} \\
\cline { 2 - 3 } Amino acid & Tau & Tau2 \\
\hline Taurine & 100 & 100 \\
Alanine & 1 & 0 \\
$\beta$-Alanine & 44 & 1 \\
Arginine & 1 & 0 \\
Asparagine & 0 & 3 \\
Aspartate & 1 & 1 \\
Cysteate & 1 & 101 \\
Cysteine & 0 & 6 \\
Cysteine sulfinate & 1 & 24 \\
GABA & 3 & 0 \\
Glutamate & 1 & 2 \\
Glutamine & 1 & 0 \\
Glycine & 1 & 1 \\
Histidine & 0 & 0 \\
Hypotaurine & 53 & 18 \\
Isoleucine & 1 & 1 \\
Leucine & 1 & 1 \\
Lysine & 6 & 3 \\
Methionine & 1 & 2 \\
Proline & 0 & 0 \\
Threonine & 0 & 0 \\
Tryptophan & 1 & 1 \\
Tyrosine & 1 & 2 \\
Valine & 0 & 1 \\
TPeren & 1 & 0
\end{tabular}

a Percentage of absorbance at $490 \mathrm{~nm}$ produced by the amino acid compared with taurine at the same concentration using the avidin-biotin method. Each value is the mean of 4 replicate wells with SE $<2 \%$.

${ }^{b}$ Concentration of amino acids added to the well for fixation was $9 \mathrm{~mm}$.

BDHC incubation time was 5 min with Tau 2 antibody and 4 min with CSADC antiserum. The BDHC reaction was stopped by excess sodium acelate buffer $(0.1 \mathrm{~m})$ and subsequent rinses in PBS. Sections were examined at the light microscopic level for the presence of brown homogeneous $\mathrm{DAB}$ reaction product and blue granular $\mathrm{BDHC}$ reaction product within cells and processes, which indicated colocalization.

Controls for the colocalization studies included the following: absorption controls of Tau2 with $1 \mathrm{mg} / \mathrm{ml}$ of original $\mathrm{KLH}$ conjugates (taurine conjugated to $\mathrm{KLH}$ ) for both the $\mathrm{DAB}$ and $\mathrm{BDHC}$ reactions, Tau 2 and CSADC as first markers on adjacent sections to compare similarity of DAB staining, elimination of either the Tau2 or CSADC primary antisera, or both, to rule out cross-reactivity caused by $A B C$ components.

\section{Results}

\section{Antibody characterization}

All characterizations of the monoclonal antibody specificities and cross-reactivities were done on amino acids fixed to thyroglobulin or $\mathrm{KLH}$ with either glutaraldehyde, paraformaldehyde, or both. Neither antibody displayed reactivity for carrier proteins, KLH or thyroglobulin, treated with glutaraldehydeborohydride in the absence of amino acids. Both monoclonal antibodies to taurine, Tau1 and Tau2, were found to possess strong ELISA reactivity for taurine and weaker reactivity for hypotaurine, fixed to thyroglobulin with glutaraldehyde (Fig. $1 A$ ). In addition, Tau1, but not Tau2, also displayed weak immunoreactivity for beta-alanine fixed to thyroglobulin using glutaraldehyde but almost no detectable immunoreactivity for other fixed amino acids (Table 1). In contrast, Tau2 displayed strong 


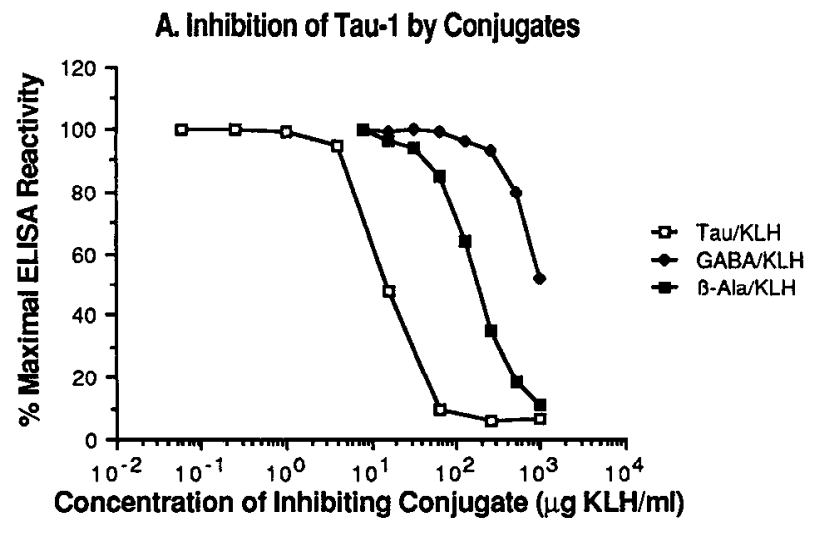

B. Inhibition of Tau-2 by Conjugates

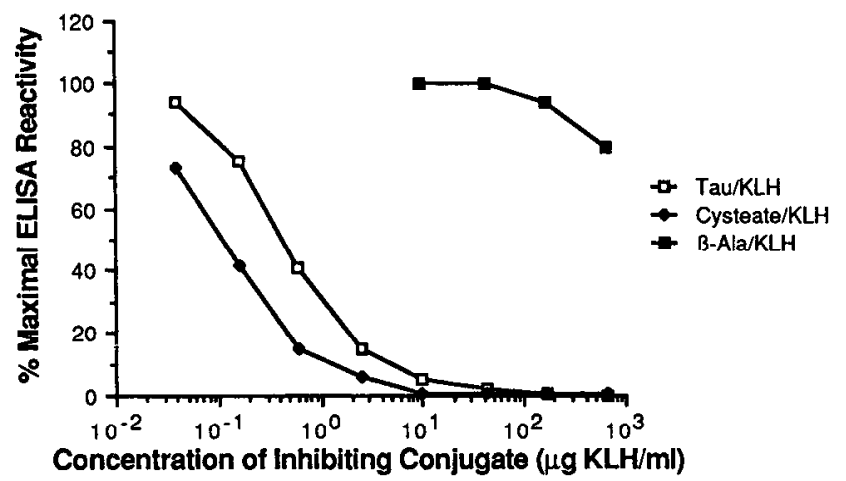

Figure 2. Inhibition of Taul and Tau2 ELISA reactivity for taurine/ $\mathrm{KLH}$ by amino acids conjugated to KLH with the use of glutaraldehyde. Each point represents the mean percentage of avidin-biotin ELISA reactivity in 3 replicate wells after preincubation of Taul and Tau 2 with conjugates of amino acids. SEs were $5 \%$ or less for the replicate wells. Tau/KLH was coated on the ELISA plates at $2 \mu \mathrm{g} / \mathrm{ml} . A$, Tau 1 culture supernatant was used at a 1:40 dilution in the assay. $B$, Tau 2 ascitic fluid was used at a 1:1000 dilution in the assay.

ELISA reactivity for cysteic acid fixed with glutaraldehyde (Fig. $1 B$ ), in addition to its strong ELISA reactivity for taurine and hypotaurine. Other amino acids were not strongly reactive with Tau2 in this assay (Table 1). Similar results were obtained with the use of $4 \%$ paraformaldehyde- $-0.3 \%$ glutaraldehyde (not shown).

In order to quantify the cross-reactivity of the antibodies for fixed amino acids, competitive inhibition ELISAs were performed (Fig. 2). The cross-reactivities for various amino acids were different for the 2 antibodies (Table 2). Taul had 10\% cross-reactivity for beta-alanine and less than $2 \%$ cross-reactivity for other amino acids in the brain, such as glutamate, GABA, cysteic acid, and cysteine sulfinate when conjugated with glutaraldehyde. Tau 2 had no detectable cross-reactivity for betaalanine fixed with glutaraldehyde but had higher binding to cysteic acid conjugates than for taurine conjugates and a weaker cross-reactivity for cysteine sulfinate conjugates. The only glutaraldehyde-fixed amino acids shown to have measurable immunoreactivity for both Taul and Tau2 were taurine and hypotaurine.

In contrast, when paraformaldehyde was used to fix the amino acids to thyroglobulin for ELISAs, Tau2 was found to have strong immunoreactiivty for taurine and hypotaurine conjugates but not for conjugates of cysteic acid, cysteine sulfinate, or other
Table 2. Cross-reactivity ${ }^{a}$ of monoclonal antibodies for glutaraldehyde-fixed amino acids determined by inhibition ELISA ${ }^{b}$

\begin{tabular}{lcc} 
Amino acid & Tau1 & Tau2 \\
\hline Taurine & 100 & 100 \\
Cysteic acid & $<2$ & 500 \\
$\beta$-Alanine & 10 & $<1$ \\
Aspartate & $<2$ & $<1$ \\
Glutamate & $<2$ & $<1$ \\
GABA & $<1$ & 2 \\
Cysteine sulfinate & 3 & 50
\end{tabular}

${ }^{a}$ Cross-reactivities, expressed as percentage, were determined from the ratio of the concentration of conjugate of an amino acid that inhibited the ELISA reactivity to 0.5 of the uninhibited value to the concentration of the taurine conjugate that inhibited the ELISA to 0.5 of the uninhibited reactivity.

${ }^{b}$ ELISAs were performed using the indirect immunoperoxidase method. At least 3 replicate wells for each concentration of conjugate were used to determine the degree of inhibition.

amino acids tested (Fig. 3, Table 3). Taul was not immunoreactive with any amino acids tested in ELISAs fixed with paraformaldehyde alone, i.e., without any glutaraldehyde.

\section{Immunohistochemical localization of taurine}

Taurine-like immunoreactivity (Tau-LI) with Tau2 in the cerebellum of rats perfused with $4 \%$ paraformaldehyde was present in a subpopulation of Purkinje cells (Fig. 4A). These bands of immunoreactive cells, and their dendrites, were separated by bands of unstained Purkinje cells (Fig. 4, $A, B$ ). This pattern of stained Purkinje cells was present in both the vermis and hemispheres of the cerebellum. Very light Tau-LI appeared to be present in Golgi, stellate, and basket cells at the light microscopic level (see Fig. 9, $C-E$ ). Tau-LI was completely absorbed by incubation of Tau2 antibody with the original antigen, taurine conjugated to $\mathrm{KLH}$ with glutaraldehyde-borohydride (Fig. 4, C, $D$ ). Tau 2 demonstrated no cross-reactivity for the original carrier protein without taurine in ELISAs.

Bands of stained Purkinje perikarya and dendrites were also present in the cerebellum of rats perfused with a $4 \%$ paraformaldehyde -glutaraldehyde $(0.2-0.4 \%)$ solution and reacted with either Tau 1 or Tau2 (Fig. 5). Occasionally, with both paraformaldehyde-glutaraldehyde and paraformaldehyde alone, only bands of stained Purkinje cell dendrites were present with no staining of associated Purkinje cell somata (Fig. 5C). The opposite was not seen, immunoreactive Purkinje cell somata were always associated with immunoreactive dendrites. Light microscopic observation and camera lucida mapping demonstrated that immunoreactivity produced by Taul and Tau 2 appeared to be present in almost identical patterns of Purkinje cells on adjacent $50 \mu \mathrm{m}$ sections (Fig. 5).

Tau-LI was more noticeable in Golgi, stellate, and basket cells fixed with paraformaldehyde-glutaraldehyde than with paraformaldehyde alone, although the staining intensity was still lighter than that present in the Purkinje cells. Examination of tissue sections at the electron microscopic level confirmed the observation that many of the stellate and basket cells contained Tau-LI (Fig. 6, $A, B$ ). Granule cells appeared to be nonimmunoreactive for both Tau2 and Taul at the light microscopic level, but a subpopulation exhibited Tau-LI at the electron microscopic level (Fig. 6C). In general, though, few immunoreactive granule cells were seen, and those that were stained tended to occur in discrete patches. Tau-LI was also present in some 
Table 3. Reactivity of Tau2 for paraformaldehyde-fixed amino acids

\begin{tabular}{lc} 
Amino acid & $\begin{array}{c}\text { ELISA reactivity } \\
\text { (\% of taurine) }\end{array}$ \\
\hline Taurine & 100 \\
Cysteate & 4 \\
Cysteine sulfinate & 1 \\
Glycine & -3 \\
Methionine & -1 \\
Valine & -1 \\
\hline
\end{tabular}

a Concentration of amino acids added to wells was $50 \mathrm{~mm}$.

${ }^{h}$ ELISA was performed using the biotin-avidin method.

mossy fibers (Fig. 7A) and in a small number of axon terminals that synapsed on basket cells (Fig. $7 B$ ) and Purkinje cells (not shown). Immunoreactive stellate and basket cells were not confined to the bands of Purkinje staining but appeared to be evenly distributed within their respective cerebellar layers at both the light and electron microscopic levels.

In general, with the use of $5 \%$ glutaraldehyde fixation, immunoreactive staining with either Taul or Tau 2 was present in the majority of Purkinje cells. Occasional unstained Purkinje perikarya were noted. Golgi, stellate, and basket cells were also stained with this fixation protocol, although, again the staining was lighter than in Purkinje cells. Taul and Tau2 immunoreactive staining obtained with each of the 3 fixation protocols was absorbed out by incubation with the original antigen.

\section{Colocalization}

Tau2 and CSADC antisera displayed similar staining patterns in a subpopulation of Purkinje cells on $50 \mu \mathrm{m}$ adjacent sections. The lack of total agreement in staining between the 2 antisera appeared to be a limitation of the use of $50 \mu \mathrm{m}$ sections. In order to confirm that the same neurons were stained by both antisera, colocalization studies were conducted using the $A B C$ technique and 2 different chromagens, DAB and BDHC.

Double-labeling of sections with Tau 2 and CSADC produced colocalization in the majority of immunoreactive neurons present, including Purkinje, Golgi, stellate, and basket cells (Figs. 8, 9). The labeling of the latter 3 cell types was more apparent in paraformaldehyde-fixed tissue on double-labeled sections than on single-labeled sections with $\mathrm{DAB}$ alone because of clustering of blue BDHC granules over the light DAB reaction (Fig. 9, $\mathrm{C}$ $E)$. Differentiation of light $\mathrm{DAB}$ and $\mathrm{BDHC}$ in the stellate cells

\section{Tau-2 ELISA Reactivity for Paraformaldehyde-fixed Amino Acids}

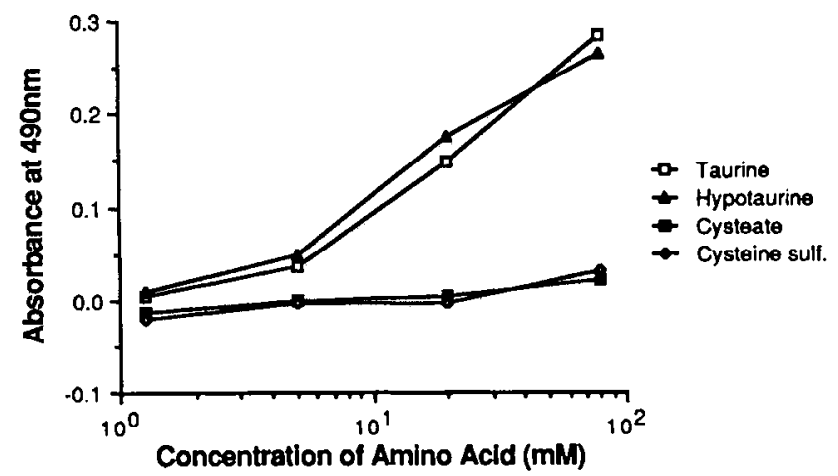

Figure 3. ELISA reactivity of Tau2 for amino acids conjugated by paraformaldehyde to thyroglobulin. Each point represents the mean absorbance of 3 replicate wells using the avidin-biotin ELISA method.

(Fig. 9D) unfortunately is more easily discernible with color microscopy than with black-and-white photography.

In the 11 animals studied, less than $10 \%$ of DAB-stained neurons did not contain any perceptible evidence of BDHC. However, BDHC was always the second marker in the doublelabeling studies, and Tau2/BDHC and CSADC/BDHC reactions were less dense on double-labeled sections compared with single-labeled sections stained with Tau2/BDHC or CSADC/ $\mathrm{BDHC}$ alone. This effect of double-labeling was more noticeable with Tau 2 as the second marker than with CSADC. The BDHC reaction product was only found to be clustered in neurons that were also labeled with the DAB reaction product. BDHC granules were found over the white matter and were sparsely located in the granule cell layer (Fig. 9C). Tau-LI, visualized with DAB, has been identified in some axons in cerebellar white matter at the electron microscopic level (unpublished observations).

Sections stained only for CSADC/DAB, adjacent to doublelabeled sections with Tau2/DAB-CSADC/BDHC, exhibited an identical staining pattern to the Tau $2 / \mathrm{DAB}$ and $\mathrm{CSADC} / \mathrm{BDHC}$ (Fig. 8). The same was true for sections stained only for Tau2/ DAB and sections double-labeled with CSADC/DAB-Tau2/ BDHC. This finding, along with a lack of BDHC granules on control sections in which the primary antibody was omitted from the $A B C-B D H C$ procedurc, ruled out the possibility that the $\mathrm{BDHC}$ was binding nonspecifically to the $\mathrm{DAB}$ reaction product. There was no staining of sections with either DAB or BDHC when associated primary antibodies were omitted. Tau2

Figure 4. Tau2 immunoreactive staining in rat cerebellum fixed with $4 \%$ paraformaldehyde. $A$, Tau 2 immunoreactive staining on a coronal section though lobule 6 of the vermis. Purkinje cells and dendrites exhibiting Tau-LI were separated by bands of unstained Purkinje cells. $M$, molecular layer; $P$. Purkinje cell layer; $G$, granule cell layer; $W$, white matter; $P^{\nu}$, Purkinje cell layer out of plane of focus. Location, bregma - 11.5 mm. $B$, High-power photomicrograph of area indicated in $A$ demonstrating Tau-LI in Purkinje cells (short solid arrows) and dendrites (long solid arrows) separated by unstained Purkinje cells (open arrows). $C$, Tau 2 immunoreactive staining in a horizontal section through lobule 3 of the vermis. $D$, Adjacent section to $C$ demonstrating that Tau-LI was completely absorbed by incubation of Tau $2(1: 40)$ with original antigen, taurine conjugated to $\mathrm{KLH}$ using glutaraldehyde-borohydride. Scale bars: $A, C$, and $D, 100 \mu \mathrm{m} ; B, 50 \mu \mathrm{m}$.

Figure 5. Tau2 and Tau 1 immunoreactive staining on coronal sections of cerebellum fixed with $4 \%$ paraformaldehyde-glutaraldehyde (0.2-0.4\%) $A$. Tau 2 immunoreactive staining on adjacent section to $B$. $B$, Taul immunoreactive staining on adjacent section to $A$. Tau 2 and Tau 1 exhibit similar staining patterns. Numbers $1-4$ in $A$ and $B$ indicate the locations of similar bands. $C$. Camera lucida drawings of adjacent sections delimiting the location (not actual numbers) of Purkinje perikarya stained with Tau-LI using either Tau2 or Taul antibodies. Asterisks indicate that bands of stained Purkinje cell dendrites were present in the lobule without stained perikarya. Dendrites were not mapped. Location, bregma - 12.3 mm. Scale bars ( $A$ and $B), 200 \mu \mathrm{m}$. 

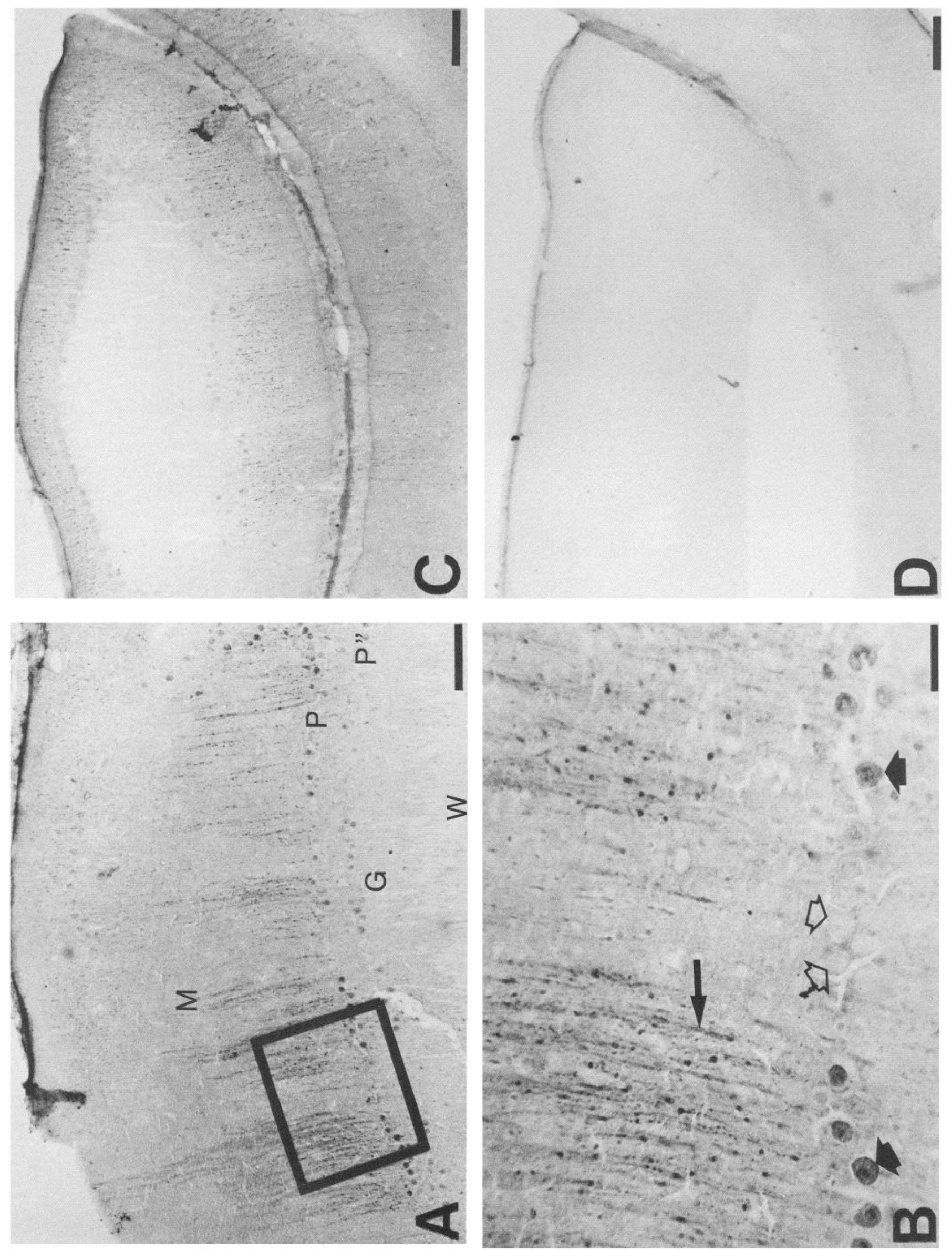

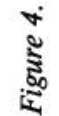



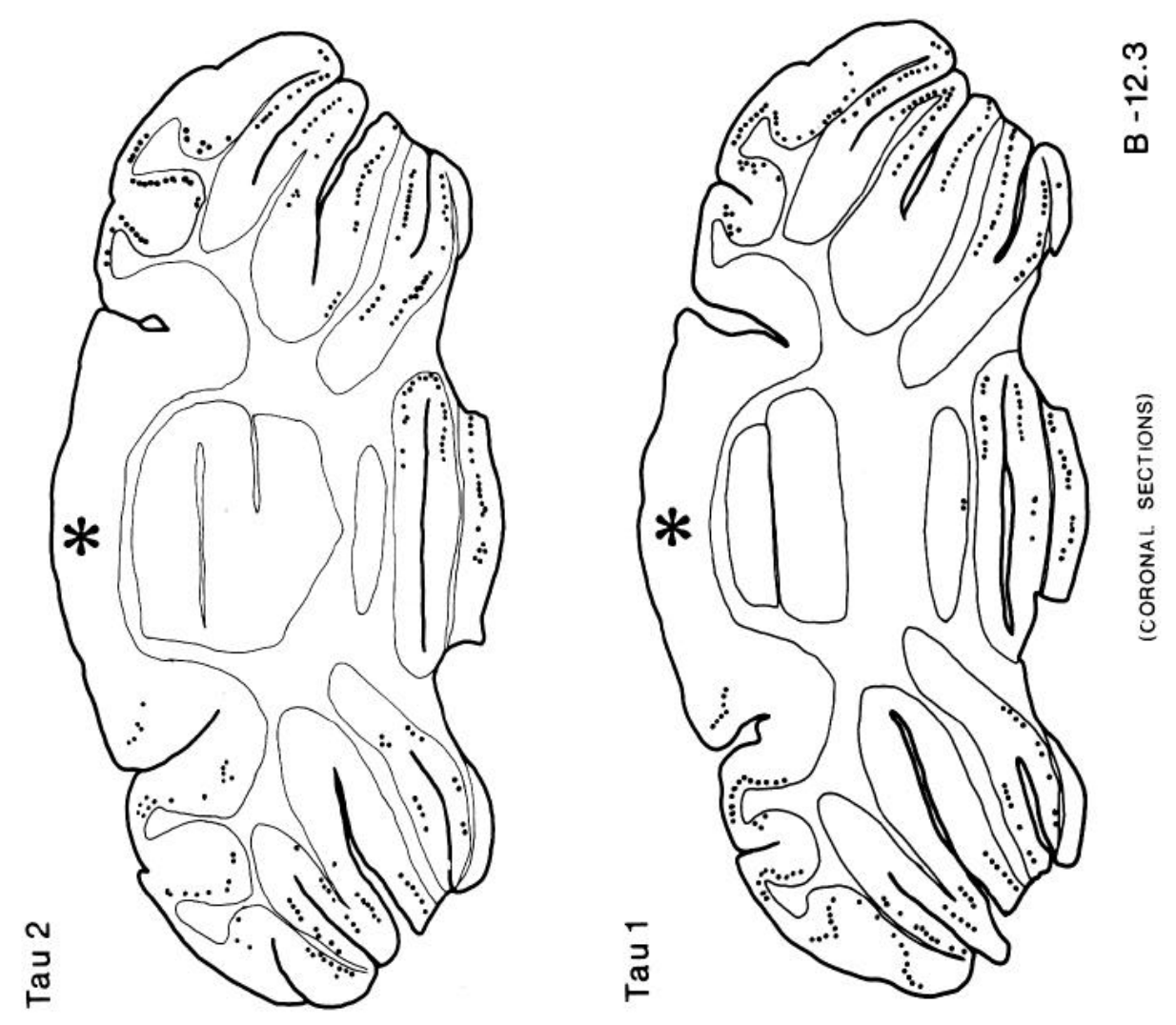

0
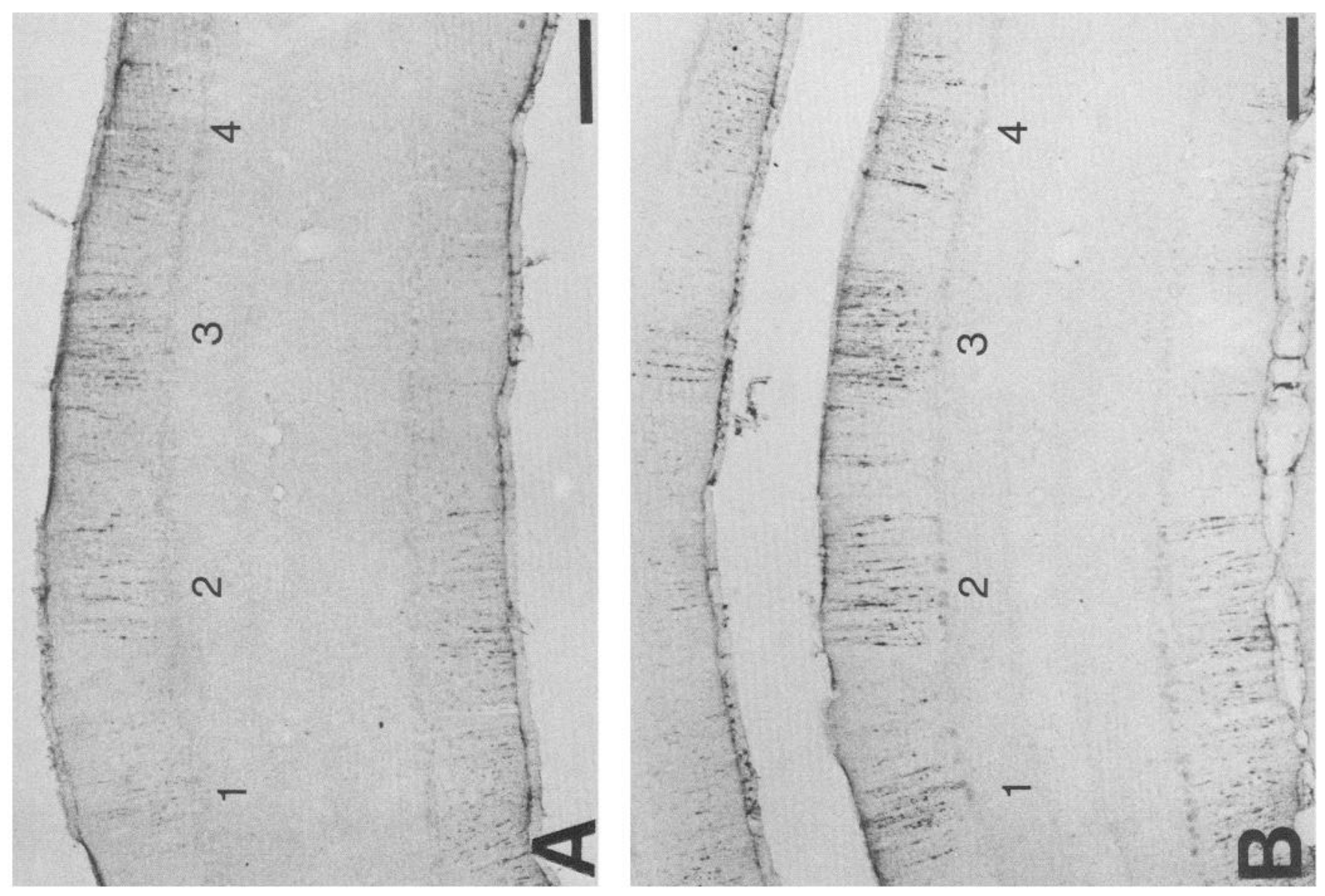

นั่ 

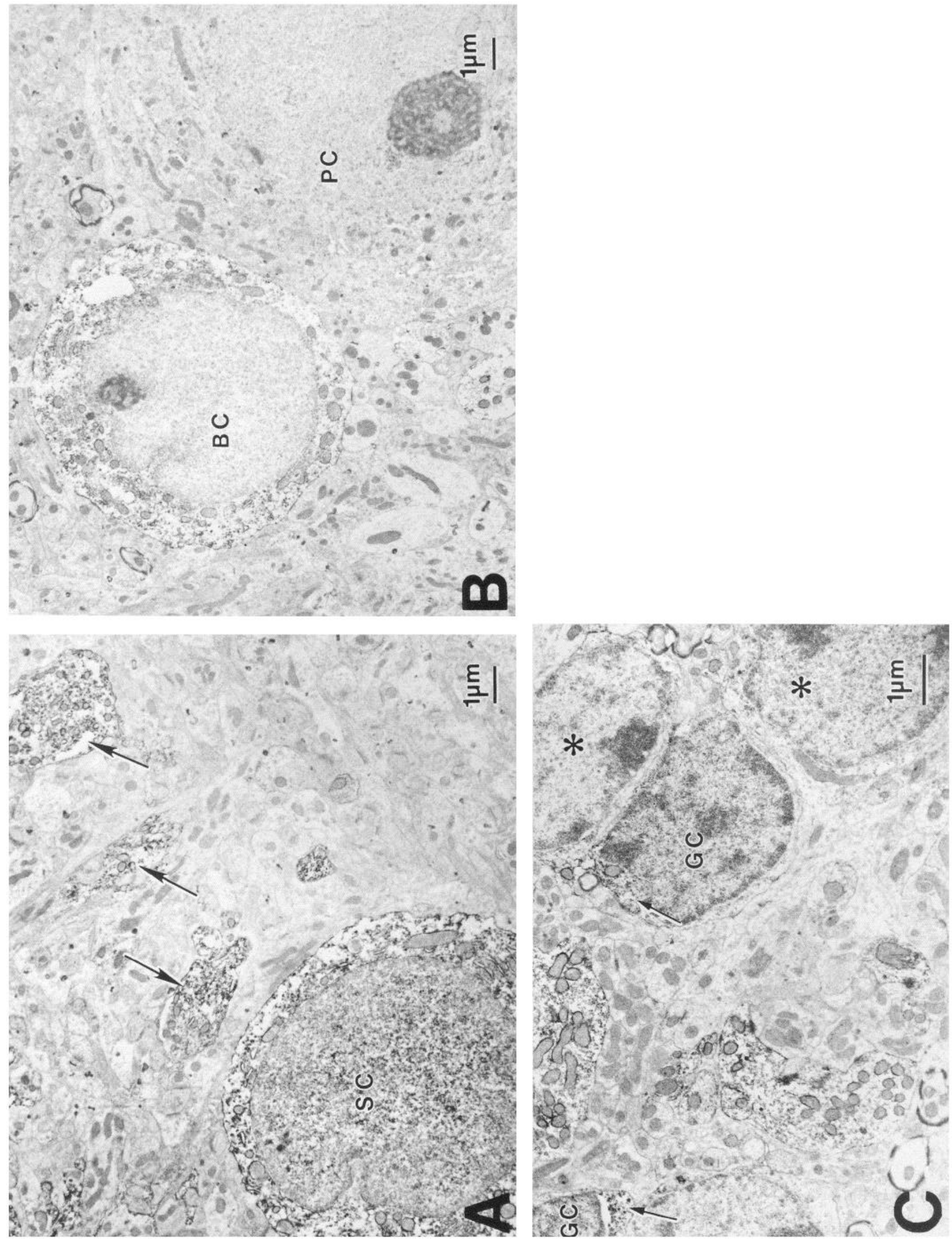

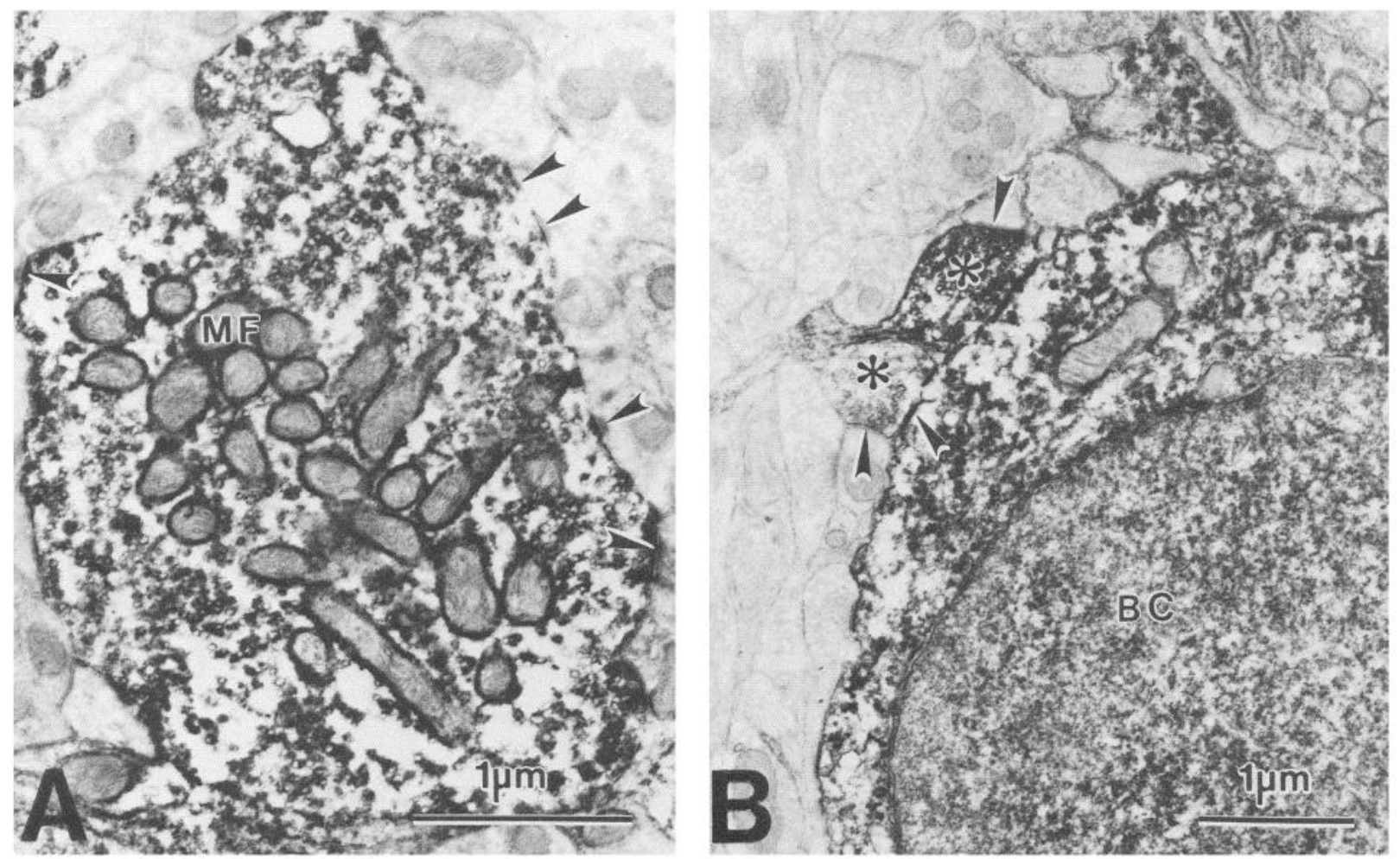

Figure 7. Taurine-like immunoreactive terminals in the cerebellar cortex. $A$, An intensely immunoreactive mossy fiber profile $(M F)$ forms numerous synapses (arrows) with nonimmunoreactive elements in the granule cell layer. (Immunoreactivity appears to be associated with synaptic vesicles.) $B$. Two immunoreactive terminals (asterisks) contact an immunoreactive basket cell $(B C)$. Both terminals appear to be forming synapses (arrows) with the basket cell and with nonimmunoreactive dendritic profiles.

staining with BDHC on both double- and single-labeled sections was absorbed by incubation of Tau2 with the original antigen.

\section{Discussion}

This study describes the production of 2 monoclonal antibodies, Taul and Tau2, which were highly selective for aldehyde-fixed taurine and which, despite different cross-reactivities in ELISAs for small molecules similar to taurine, exhibited identical immunohistochemical staining patterns in the cerebellum of the rat. The Tau1 and Tau2 antibodies also displayed a similar staining pattern to that obtained using antiserum against an enzyme marker for taurine-containing neurons, CSADC. Indeed, we have shown in the present study that Tau2 and CSADC immunoreactivities are colocalized in Purkinje, Golgi, stellate, and basket cells of the rat cerebellum. Tau2 and CSADC also have been colocalized in neurons within the hippocampus (Magnusson et al., 1987).

Tau2 displayed cross-reactivity for both cysteic acid (CA) and cysteine sulfinic acid (CSA) when glutaraldehyde or paraformaldehyde-glutaraldehyde fixation was used. This problem was circumvented, in the majority of experiments presented in this study, by fixing the brain tissue with paraformaldehyde alone. Tau2 shows little or no cross-reactivity for CA or CSA in ELISAs with paraformaldehyde alone.
On adjacent $50 \mu \mathrm{m}$ thick brain sections fixed with paraformaldehyde-glutaraldehyde, Tau1 and Tau2 exhibited almost identical staining patterns (Fig. 5), despite the differences in cross-reactivities between the 2 antibodies in ELISAs. The lack of total agreement of staining between the 2 antibodies is probably a limitation of the use of $50 \mu \mathrm{m}$ sections. Taul exhibited much lower cross-reactivity for CA or CSA conjugates than did Tau2, and Tau2 had a much lower cross-reactivity with betaalanine conjugates than did Taul. The low concentration of CA and CSA in the rat brain, compared with taurine, would suggest that CA and CSA probably constitute a very minor proportion of Tau2 antibody binding in glutaraldehyde-fixed rat brain. Kuriyama and coworkers (1986) reported that the amount of CSA and CA in the cerebellum of Wistar Kyoto rats is 27.5 and 11.6 $\mathrm{nmol} / \mathrm{gm}$ wet weight, respectively. Taurine levels in the cerebellum are $4.7 \mu \mathrm{mol} / \mathrm{gm}$ wet weight, a 200 - to 400 -fold difference in concentration. Comparable differences in concentrations of these amino acids occur in other brain regions (Kuriyama et al., 1986). Based on the comparison of Tau 2 immunostaining with Taul immunostaining and the tissue concentration differences, we conclude that either CA and CSA concentrations were too low to be detected by Tau2 in this study or the CA and/or CSA labeled by Tau2 were present in the same neurons as taurine, where they may serve as precursors for taurine.

Figure 6. Taurine-like immunoreactive neurons in the cerebellar cortex. $A$, An immunoreactive stellate cell $(S C)$ is immunostained with Tau2. Numerous large immunoreactive dendritic profiles (arrows) are also evident. (These profiles are probably Purkinje cell dendrites.) $B$, An immunoreactive basket cell $(B C)$ adjacent to a nonimmunoreactive Purkinje cell $(P C)$. $C$, In the granule cell layer, lightly immunostained granule cells (asterisks). Arrows indicate the reaction product in the immunostained granule cells. 

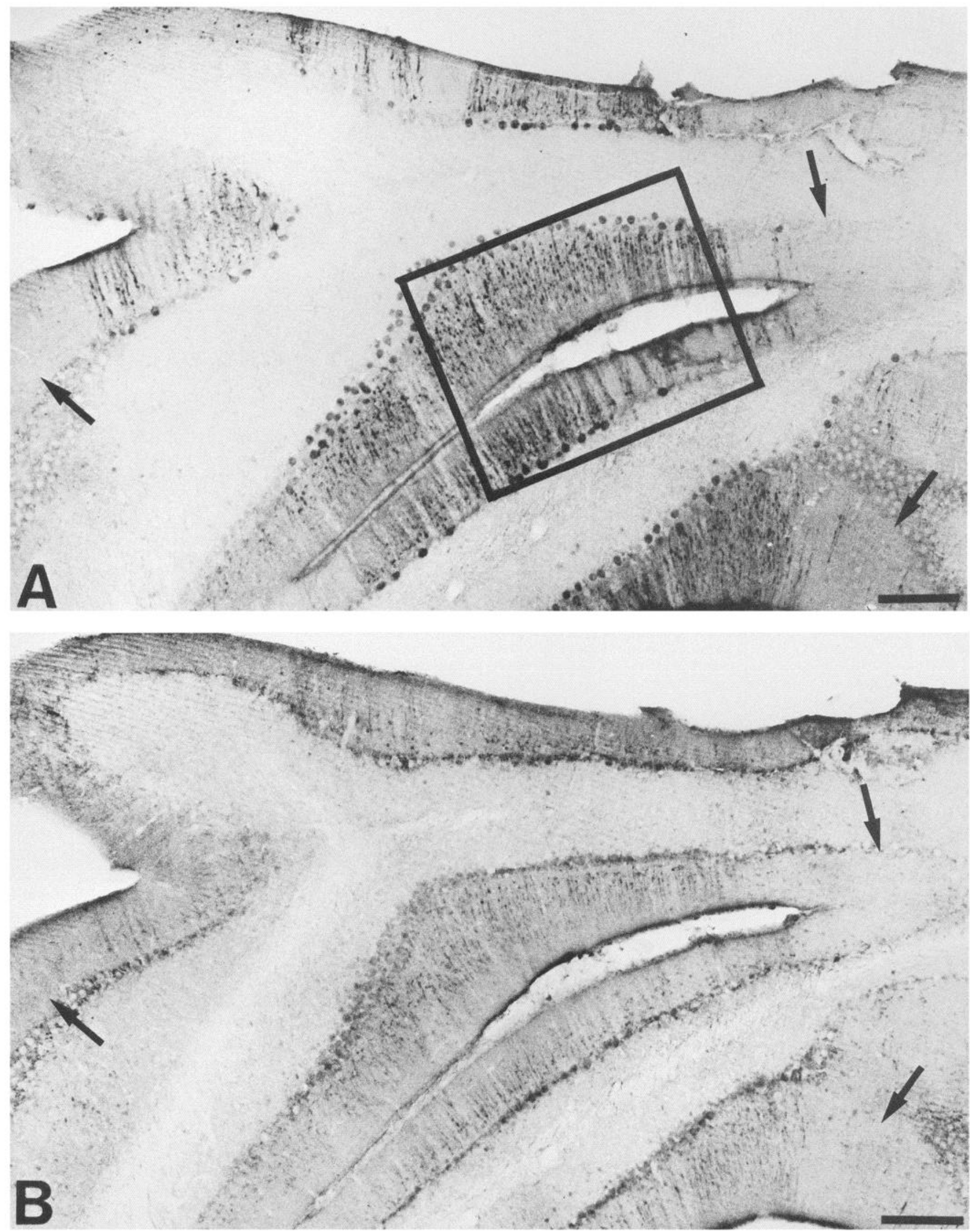

Figure 8. Double labeling of Tau2 and CSADC antisera exhibit the same pattern of staining as each of the antisera alone. A, Coronal section double-labeled with Tau2/DAB and CSADC/BDHC. See Figure 9 for detail of double-labeling. $B$, Control adjacent section to $A$ demonstrating that CSADC/DAB labeling alone was similar to CSADC/BDHC and Tau2/DAB labeling on double-labeled sections, as in $A$. $A$ and $B$ have similar stained and unstained areas (arrows). Scale bars $(A$ and $B), 200 \mu \mathrm{m}$. 
Chan-Palay and coworkers (1982b) were the first to describe the presence of CSADC-like immunoreactivity, a proposed marker for taurinc-containing neurons, in sagittal microbands in the cerebellum. They reported staining in Purkinje, Golgi, stellate, and basket cells. The similarity of staining of Taul and Tau2 in the cerebellum to that reported by Chan-Palay et al. (1982b) led us to attempt to colocalize the 2 proposed taurinergic cell markers. Tau2 and CSADC antisera were found to be colocalized within neurons of the rat cerebellum. The lack of total colocalization appeared to be a limitation of the double-labeling technique. The $\mathrm{BDHC}$ reaction product uniformly appeared less dense on double-labeled sections than on sections labeled with $\mathrm{BDHC}$ alone. This suggests that the first primary antibody, $\mathrm{ABC}$ complex and/or $\mathrm{DAB}$ reaction interfered with binding of the second primary antibody by covering antigenic sites. This interference may have caused the total absence of BDHC granules on some DAB-labeled cells that might have been present in the absence of the first antibody/DAB complex. Given this limitation, the lack of clustering of Tau $2 / \mathrm{BDHC}$ or CSADC/BDHC reaction product over neurons without DAB staining supports the conclusion that the 2 markers are colocalized within neurons of the cerebellum. The results of the controls performed ruled out nonspecific cross-reactivity between the 2 markers in the colocalization studies.

Several groups (Madsen et al., 1985; Campistron et al., 1986; Tomida and Kimura, 1987), with the use of glutaraldchydc fixation, reported taurine-like immunoreactivity in all, or a majority of, Purkinje cells and in few Golgi, stellate, and basket cells of the rat cerebellum. The tissue in which we report the presence of immunostained Purkinje cell bands was fixed with either paraformaldehyde or paraformaldehyde-glutaraldehyde. On tissue fixed with $5 \%$ glutaraldehyde, Tau1 and Tau 2 stained the majority of Purkinje cell perikarya and dendrites. Thus, our results with glutaraldehyde-fixed tissue were similar to that reported by others (Madsen et al., 1985; Campistron et al., 1986; Tomida and Kimura, 1987). Tau-LI, obtained with Taul or Tau2, also was present in Golgi, stellate, and basket cells. These neurons, however, were stained more lightly than the Purkinje cells and only represent a subpopulation of their total respective populations.

Yoshida et al. (1986) mentioned the presence of weak, or unstained, Purkinje cells among the stained Purkinje cells with the use of paraformaldehyde-glutaraldehyde fixed tissue. This is similar to our staining with paraformaldehyde and paraformaldehyde-glutaraldehyde. Glutaraldehyde is a more efficient fixative for amino acids than is paraformaldehyde (Ottersen et al., 1985). However, we were able to measure immunoreactivity for taurine and hypotaurine fixed to carrier proteins with paraformaldehyde in ELISAs (Fig. 3). It is possible that, with a less effective fixative such as paraformaldehyde, only those neurons containing a higher concentration of taurine were stained with an equivalent intensity. The colocalization studies indicate that this subpopulation of neurons, with Tau-LI, also contain the CSADC enzyme and might therefore contain a higher concentration of taurine because of their ability to synthesize this amino acid. It has been demonstrated that fixation of certain amino acids can be hindered by the presence of other amino acids (Ottersen et al., 1986). It is possible that the unstained Purkinje cells observed in paraformaldehyde-fixed tissue contained a higher concentration of other amino acids, such as GABA, which interfered with the fixation of taurine. However, the presence of colocalized CSADC in neurons stained with Tau-LI suggests that this is a unique subpopulation of Purkinje cells.

The significance of the bands of Purkinje cells containing TauLI and CSADC-LI is, as yet, unknown (Chan-Palay et al., 1982b). A banded staining pattern with both antisera was also present in tissue that was immersion fixed with $4 \%$ paraformaldehyde (unpublished observations). This would argue against the bands being merely a result of variations in fixation during perfusion. Previous reports have identified similar subpopulations of cerebellar Purkinje cells containing GABA and/or motilin (ChanPalay et al., 1981; Chan-Palay, 1983) or bands of Purkinje cells positively and negatively stained with monoclonal antibodies raised against a component of a cerebellar homogenate (Hawkes et al., 1985). Longitudinal patterns of climbing fiber projections (Groenewegen and Voogd, 1976; Oscarsson, 1976; Voogd et al., 1985; Logan and Robertson, 1986; Robertson and Logan, 1986), mossy fiber projections (Oscarsson, 1976; Voogd et al., 1985), Purkinje cell axons (Feirbend et al., 1976), and acetylcholinesterase (Hess and Voogd, 1986; Robertson and Logan, 1986), and cytochrome oxidase (Hess and Voogd, 1986) localizations exist in the cerebellum. The relationship between the subpopulation of taurine neurons identified in this study and other longitudinal cerebellar patterns remains to be determined.

Studies have suggested that taurine acts as a neurotransmitter for stellate interneurons in the cerebellum (Nadi et al., 1977; Frederickson et al., 1978; McBridc and Frcderickson, 1980; Okamoto and Sakai, 1980; Okamoto et al., 1983a-c). Some anatomical studies report tritiated taurine uptake into cerebellar interneurons (Chan-Palay et al., 1982a) and CSADC-LI in the same interneurons; i.e., Golgi, stellate, and basket cells (ChanPalay et al., 1982a, b). Assumpcao and coworkers (1979), however, reported tritiated taurine uptake into Purkinje cells and dendrites but not in interneurons. The majority of taurine immunohistochemistry studies report weak or no staining of cerebellar stellate and basket cells (Madsen et al., 1985; Campistron et al., 1986; Yoshida et al., 1986; Tomida and Kimura, 1987). Our antibodies stained these cells lightly. Madsen et al. (1985) reported no evidence of Tau-LI in nerve terminals in the molecular layer, and Yoshida et al. (1986) reported a lack of basket cell terminals containing Tau-LI. These reports, therefore, do not support the theory of taurine acting as a major neurotransmitter for stellate or basket cells.

In the present study, Tau-LI was present in some mossy fibers and in some terminals that synapsed on Purkinje cells and basket cells. These results may provide evidence for a neurotransmitter role of taurine in the cerebelium; however, taurine has been shown to modulate the synaptic release of transmitters such as ACh, norepinephrine, and GABA (Kuriyama, 1980). Researchers have proposed that some mossy fibcrs use the excitatory amino acid glutamate as a neurotransmitter (Freeman et al., 1983; Beitz et al., 1986; Somogyi et al., 1986; Wenthold et al., 1986). We believe that taurine is more likely to serve in a neuromodulatory role in these excitatory fibers than in a classical transmitter role.

Taurine is more effective at causing hyperpolarization on the Purkinje cell dendrite than on the soma (Frederickson et al., 1978; Okamoto and Sakai, 1980; Okamoto et al., 1983a, b). Calcium is the ion primarily responsible for dendritic excitability in Purkinje cells (Llinás and Sugimori, 1980). Taurine reportedly blocks dendritic calcium spikes by preventing further influx of calcium into the dendrite (Okamoto et al., 1983a). 


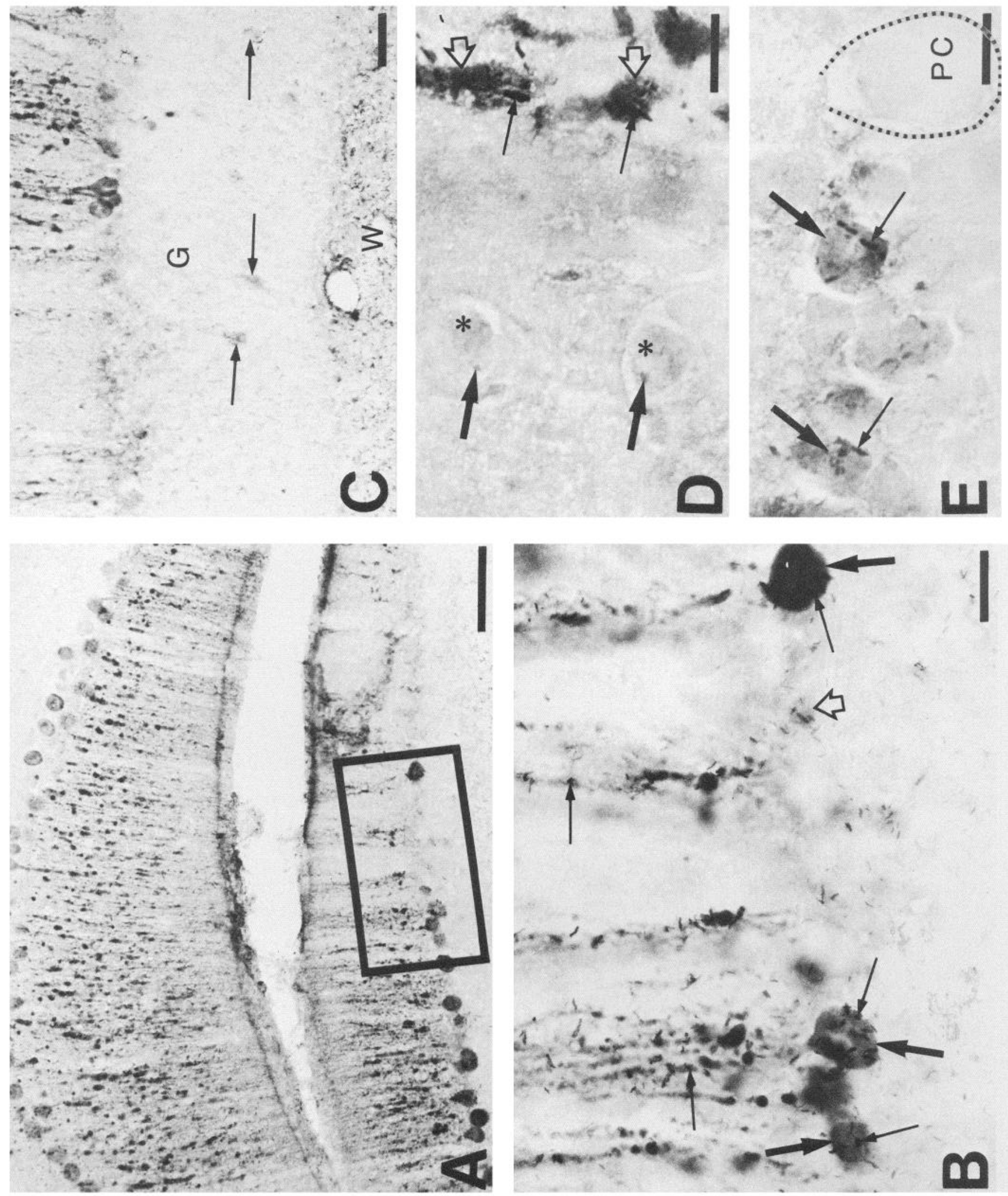


Taurine release in the cerebellum also has been demonstrated to be calcium dependent (Bernardi et al., 1977, 1978). In our study, the presence of Tau-LI was most prominent in Purkinje cell dendrites, followed by the soma, and light Tau-LI in cerebellar interneurons. Nonsynaptic release of taurine has been shown in hippocampus (Lehmann et al., 1986) and optic nerve (Kuriyama, 1980). The electrically stimulated, calcium-dependent release of taurine in cerebellar slices (Bernardi et al., 1978) could, therefore, be due to release of taurine from the postsynaptic Purkinje cell dendrite in response to a calcium-linked depolarization, as has been described in pyramidal cell dendrites with N-methyl-D-aspartate (Lehmann et al., 1985). Taurineinduced hyperpolarization of Purkinje cell dendrites, which has been attributed to the release of taurine by stellate cells, may be caused by calcium-stimulated release of taurine from the postsynaptic Purkinje cell dendrite in a negative-feedback mechanism. The released taurine would then function to modulate further influx of calcium and control the excitability of the cell.

In summary, Taul and Tau2, monoclonal antibodies with high affinity for aldehyde-fixed taurine, exhibit almost identical immunoreactive staining patterns in a subpopulation of Purkinje cell dendrites and soma and light immunoreactivity within Golgi, stellate, and basket cells. These neurons containing Tau$\mathrm{LI}$ also contain the enzyme CSADC, suggesting that this subpopulation of neurons can produce taurine. Prominent Purkinje cell dendritic staining and lack of numerous terminals in the molecular layer provide anatomical evidence to suggest that the calcium-linked depolarization of Purkinje dendrites may cause a rclcase of taurine from the dendrites, which then functions to prevent further depolarization. Thus, the results of this study suggest a neuromodulator role for taurine in the cerebellum.

\section{References}

Agrawal, H. C., A. N. Davison, and L. K. Kaczmarek (1971) Subcellular distribution of taurine and cysteine-sulphinate decarboxylase in developing rat brain. Biochem. J. 122: 759-763.

Assumpcao, J. A., N. Bernardi, C. G. Dacke, N. Davidson, and H. G. Eichelberger (1979) Purkinje cell uptake in vivo of [3H] taurine in the rat cerebellum. J. Physiol., (Lond.) 298: 35P-36P.

Barbeau, A., S. Melancon, R. J. Huxtable, and B. Lemieux (1982) Taurine and Friedreich's ataxia: An update. Adv. Exp. Med. Biol. 139: 389-399.

Beitz, A. J., A. A. Larson, P. Monaghan, R. A. Altschuler, M. A. Mullett, and J. E. Madl (1986) Immunohistochemical localization of glutamate, glutaminase and aspartate aminotransferase in neurons of the pontine nuclei of the rat. Neuroscience 17:741-753.

Bernardi, N., J. A. Assumpcao, C. G. Dacke, and N. Davidson (1977) Calcium-dependent increase in efflux of $[1-3 \mathrm{H}]$ taurine from the superfused rat cerebellar cortex in vivo. Pfluegers Arch. 372: 203-205.

Bernardi, N., C. G. Dacke, and N. Davidson (1978) Increased in vivo [1-3H] taurine efflux from cerebellar cortex by direct electrical stimulation. J. Physiol. (Lond.) 280: 14P.

Campistron, G., M. Geffard, and R. M. Buijs (1986) Immunological approach to the detection of taurine and immunocytochemical results. J. Neurochem. 46: 862-868.
Chan-Palay, V. (1983) Immunocytochemical and autoradiographic methods to demonstrate the coexistence of neuroactive substance: Cerebellar Purkinje cells have glutamic acid decarboxylase, cysteine sulfinic acid decarboxylase, and motilin immunoreactivity. Acta Morphol. Hung. 31: 193-212.

Chan-Palay, V., G. Nilaver, S. L. Palay, M. C. Beinfield, E. A. Zimmerman, J.-Y. Wu, and T. L. O'Donohue (1981) Chemical heterogeneity in cerebellar Purkinje cells: Existence and coexistence of glutamic acid decarboxylase-like and motilin-like immunoreactivities. Proc. Natl. Acad. Sci. USA 78: 7787-7791.

Chan-Palay, V., C.-T. Lin, S. Palay, M. Yamamoto, and J.-Y. Wu (1982a) Taurine in the mammalian cerebellum: Demonstration by autoradiography with $[3 \mathrm{H}]$ taurine and immunocytochemistry with antibodies against the taurine-synthesizing enzyme, cysteine-sulfinic acid decarboxylase. Proc. Natl. Acad. Sci. USA 79: 2695-2699.

Chan-Palay, V., S. L. Palay, and J.-Y. Wu (1982b) Sagittal cerebellar microbands of taurine neurons: Immunocytochemical demonstration by using antibodies against the taurine-synthesizing enzyme cysteine sulfinic acid decarboxylase. Proc. Natl. Acad. Sci. USA 79: 42214225 .

Curtis, D. R., J. D. I eah, and M. J. Peet (1982) Lack of specificity of a "taurine antagonist." Brain Res. 244: 198-199.

Feirbend, H. K. P., G. J. Vielvoye, S. L. Freedman, and J. Voogd (1976) Longitudinal organization of afferent and efferent connections of the cerebellar cortex of the white leghorn (Gallus domesticus). Exp. Brain Res. (Suppl.) 1: 72-78.

Frederickson, R. C. A., M. Neuss, S. L. Morzorati, and W. J. McBride (1978) A comparison of the inhibitory effects of taurine and GABA on identified Purkinje cells and other neurons in the cerebellar cortex of the rat. Brain Res. 145: 117-126.

Freeman, M. E., J. D. Lane, and J. E. Smith (1983) Turnover rates of amino acid neurotransmitters in regions of rat cerebellum. J. Neurochem. 40: 1441-1447.

Groenewegen, H. J., and J. Voogd (1976) The longitudinal zonal arrangement of the olivocerebellar, climbing fiber projection in the cat. An autoradiographic and degeneration study. Exp. Brain Res. (Suppl.) 1: $65-71$.

Hastings, D. F., J. D. Welty, and F. Rohani (1985) Taurine stimulation of isolated hamster brain Na,K-ATPase: Activation kinetics and chemical specificity. J. Neurochem. 44: 1764-1770.

Hawkes, R., M. Colonnier, and N. Leclerc (1985) Monoclonal antibodies reveal sagittal banding in the rodent cerebellar cortex. Brain Res. 333: 359-365.

Hess, D. T., and J. Voogd (1986) Chemoarchitectonic zonation of the monkey cerebellum. Brain Res. 369: 383-387.

Huxtable, R. J., and L. A. Sebring (1986) Towards a unifying theory for the actions of taurine. Trends Pharmacol. Sci. 7: 481-485.

Izumi, K., T. T. Ngo, and A. Barbeau (1978) Metabolic modulation in the central nervous system by taurine. In Taurine and Neurological Disorders, A. Barbeau and R. J. Huxtable, eds., pp. 137-149, Raven, New York.

Kontro, P., and S. S. Oja (1978) Sodium dependence of taurine uptake in rat brain synaptosomes. Neuroscience 3: 761-765.

Kontro, P., and S. S. Oja (1983) Taurine and synaptic transmission. Med. Biol. 61: 79-82.

Kuriyama, K. (1980) Taurine as a neuromodulator. Fed. Proc. 39: 2680-2684.

Kuriyama, K., S. Ida, Y. Tanaka, and S. Ohkuma (1986) Decreased taurine biosynthesis in the brain of spontaneously hypertensive rat. J. Hypertension (Suppl. 3) 4: S175-S176.

Lakos, S., and A. I. Basbaum (1986) Benzidine dihydrochloride as a chromagen for single- and double-label light and electron microscopic immunocytochemical studies. J. Histochem. Cytochem. 34: 10471056.

$\leftarrow$

Figure 9. Tau2 and CSADC antisera are colocalized within neurons of the cerebellum. $A$, Higher-magnification photomicrograph of area indicated in Figure $8 A$ demonstrating the presence of Tau2/DAB (stained neurons) and CSADC/BDHC (granules over neurons) colocalized in Purkinje cell perikarya and dendrites. $B$, High-magnification photomicrograph of area indicated in $A$ demonstrating Purkinje cells stained with Tau $2 / D A B$ (homogeneous light stain; large arrows) that also contain CSADC/BDHC staining (granules; small arrows). Tau2 and CSADC are also colocalized in basket cells (open arrow). $C$, Photomicrograph of Golgi cells (small arrows) within the granule cell layer $(G)$ that contain both Tau2/DAB and CSADC/BDHC. The white matter $(W)$ is stained with CSADC/BDHC. $D$, High-power photomicrograph of light Tau $2 / \mathrm{DAB}($ asterisks) and CSADC/ BDHC (large arrows) staining in stellate cells of the molecular layer. Both Tau2 and CSADC labels are lighter in stellate cells than the Purkinje cell dendrites stained with Tau2 (open arrows) and CSADC (small arrows). E, High-power photomicrograph of Tau2/DAB (large arrows) and CSADC/BDHC (small arrows) in basket cells [unstained Purkinje cell (PC and dotted outline)]. Scale bars: $A, 100 \mu \mathrm{m} ; B, 25 \mu \mathrm{m} ; C, 50 \mu \mathrm{m} ; D$ and $E, 10 \mu \mathrm{m}$. 
Lehmann, A., J. W. Lazarewicz, and M. Zeise (1985) N-methylaspartate-evoked liberation of taurine and phosphoethanolamine in vivo: Site of release. J. Neurochem. 45: 1172-1177.

Lehmann, A., H. Hagberg, J. W. Lazarewicz, I. Jacobson, and A. Hamberger (1986) Alterations in extracellular amino acids and calcium following excitotoxin administration and during status epilepticus. Adv. Exp. Med. Biol. 203: 363-373.

Llinás, R., and M. Sugimori (1980) Electrophysiological properties of in vitro Purkinje cell dendrites in mammalian cerebellar slices. J. Physiol. (Lond.) 305: 197-213.

Logan, K., and L. T. Robertson (1986) Somatosensory representation of the cerebellar climbing fiber system in the rat. Brain Res. 372:290300 .

Lombardini, J. B. (1976) Regional and subcellular studies on taurine in the rat central nervous system. In Taurine, R. Huxtable and A. Barbeau, eds., pp. 311-326, Raven, New York.

Madl, J. E., A. A. Larson, and A. J. Beitz (1986) Monoclonal antibody specific for carbodiimide-fixed glutamate: Immunocytochemical localization in the rat CNS. J. Histochem. Cytochem. 34: 317-326.

Madl, J. E., A. J. Beitz, R. L. Johnson, and A. A. Larson (1987) Monoclonal antibodies specific for fixative-modified aspartate: Immunocytochemical localization in the rat CNS. J. Neurosci. 7: 26392650.

Madsen, S., O. P. Ottersen, and J. Storm-Mathisen (1985) Immunocytochemical visualization of taurine: Neuronal localization in the rat cerebellum. Neurosci. Lett. 60: 255-260.

Magnusson, K. R., J. E. Madl, A. A. Larson, J.-Y. Wu, and A. J. Beitz (1987) Immunohistochemical co-localization of taurine-like and CSAD-like immunoreactivity in the hippocampus of the rat. Neurosci. Suppl. 22: S122.

McBride, W. J., and R. C. A. Frederickson (1980) Taurine as a possible inhibitory transmitter in the cerebellum. Fed. Proc. 39: 2701-2705.

Meiner, B. A., R. C. Speth, N. Bresolin, R. J. Huxtable, and H. I. Yamamura (1980) Sodium-dependent, high-affinity taurine transport into rat brain synaptosomes. Fed. Proc. 39: 2695-2700.

Nadi, N. S., W. J. McBride, and M. H. Aprison (1977) Distribution of several amino acids in regions of the cerebellum of the rat. $\mathrm{J}$. Neurochem. 28: 453-455.

Oja, S. S., and P. Kontro (1978) Neurotransmitter actions of taurine in the central nervous system. In Taurine and Neurological Disorders, A. Barbeau and R. J. Huxtable, eds., pp. 181-200, Raven, New York.

Oja, S. S., and P. Lahdesmaki (1974) Is taurine an inhibitory neurotransmitter? Med. Biol. 52: 138-143.

Okamoto, K., and Y. Sakai (1980) Localization of sensitive sites to taurine, gamma-aminobutyric acid, glycine, and beta-alanine in the molecular layer of guinea-pig cerebellar slices. Br. J. Pharmacol. 69: 407-413.

Okamoto, K., H. Kimura, and Y. Sakai (1983a) Effects of taurine and GABA on $\mathrm{Ca}$ spikes and Na spikes in cerebellar Purkinje cells in vitro: Intrasomatic study. Brain Res. 260: 249-259.

Okamoto, K., H. Kimura, and Y. Sakai (1983b) Ionic mechanisms of the action of taurine on cerebellar Purkinje cell dendrites in vitro: Intradendritic study. Brain Res. 260: 261-269.

Okamoto, K., H. Kimura, and Y. Sakai (1983c) Evidence for taurine as an inhibitory neurotransmitter in cerebellar stellate interneurons: Selective antagonism by TAG (6-aminomethyl-3-methyl-4H,1,2,4benzothiadiazine-1,1-dioxide). Brain Res. 265: 163-168.
Oscarsson, O. (1976) Spatial distribution of climbing and mossy fibre inputs into the cerebellar cortex. Exp. Brain Res. (Suppl.) 1: 36-42.

Ottersen, O. P., S. Madsen, B. S. Meldrum, and J. Storm-Mathisen (1985) Taurine in the hippocampal formation of the Senegalese baboon, Papio papio: An immunocytochemical study with an antiserum against conjugated taurine. Exp. Brain Res. 59: 457-462.

Ottersen, O. P., J. Storm-Mathisen, S. Madsen, S. Skumlien, and J. Stromhaug (1986) Evaluation of the immunocytochemical method for amino acids. Med. Biol. 64: 147-158.

Palkovits, M., I. Elekes, I. Lang, and A. Patthy (1986) Taurine levels in discrete brain nuclei of rats. J. Neurochem. 47: 1333-1335.

Perry, T. L. (1978) Taurine in dominantly inherited cerebellar atrophies and other human neurological disorders. In Taurine and Neurological Disorders, A. Barbeau and R. J. Huxtable, eds., pp. 441451, Raven, New York.

Robertson, L. T., and K. Logan (1986) Relationship of parasagittal bands of acetylcholinesterase activity to the climbing fiber representation. Neurosci. Lett. 72: 128-134.

Schaffer, S. W., J. Kramer, and J. P. Chovan (1980) Regulation of calcium homeostasis in the heart by taurine. Fed. Proc. 39: 26912694.

Somogyi, P., K. Halasy, J. Somogyi, J. Storm-Mathisen, and O. P. Ottersen (1986) Quantification of immunogold labeling reveals enrichment of glutamate in mossy and parallel fibre terminals in cat cerebellum. Neuroscience 19: 1045-1050.

Sugimoto, T., K. Itoh, Y. Yasui, T. Kaneko, and N. Mizuno (1985) Coexistence of neuropeptides in projection neurons of the thalamus in the cat. Brain Res. 347: 381-384.

Tomida, Y., and H. Kimura (1987) Immunohistochemical and biochemical studies of substances with taurine-like immunoreactivity in the brain. Acta Histochem. Cytochem. 20: 31-40.

Voogd, J., N. M. Gerritts, and E. Marani (1985) Cerebellum. In The Rat Nervous System, G. Paxinos, ed., pp. 251-291, Academic, Sydney.

Wenthold, R. J., K. K. Skaggs, and R. A. Altschuler (1986) Immunocytochemical localization of aspartate aminotransferase and glutaminase immunoreactivities in the cerebellum. Brain Res. 363:371375.

Wu, J.-Y. (1982) Purification and characterization of cysteic acid and cysteine sulfinic acid decarboxylase and L-glutamate decarboxylase from bovine brain. Proc. Natl. Acad. Sci. USA 79: 4270-4274.

Wu, J.-Y., C.-T. Lin, B. Hwang, H. S. Lin, and S. Wei (1986) Antibodies against enzymes synthesizing amino acid transmitters. In $\mathrm{Neu}$ rohistochemistry: Modern Methods and Applications, P. Panula, H. Paivarinta, and S. Soinila, eds., pp. 21-47, Liss, New York.

Yarborough, G. G., D. K. Singh, and D. A. Taylor (1981) Neuropharmacological characterization of a taurine antagonist. J. Pharmacol. Exp. Ther. 219: 604-613.

Yeh, H. H., H. C. Moises, B. D. Waterhouse, and D. J. Woodward (1981) Modulatory interactions between norepinephrine and taurine, beta-alanine, gamma-aminobutyric acid and muscimol applied iontophoretically to cerebellar Purkinje cells. Neuropharmacology 20: 549-560.

Yoshida, M., N. Karasawa, M. Ito, M. Sakai, and I. Nagatsu (1986) Demonstration of taurine-like immunoreactive structures in the rat brain. Neurosci. Res. 3: 356-363. 